\title{
Climate change in the next 30 years: What can a convection-permitting model tell us that we did not already know?
}

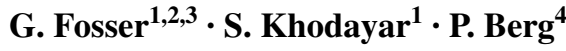

Received: 7 May 2015 / Accepted: 19 May 2016 / Published online: 17 June 2016

(C) The Author(s) 2016. This article is published with open access at Springerlink.com

\begin{abstract}
To investigate the climate change in the next 30 years over a complex terrain in southwestern Germany, simulations performed with the regional climate model COSMO-CLM at convection-permitting resolution are compared to simulations at $7 \mathrm{~km}$ resolution with parameterised convection. An earlier study has shown the main benefits of convection-permitting resolution in the hourly statistics and the diurnal cycle of precipitation intensities. Here, we investigate whether the improved simulation of precipitation in the convection-permitting model is affecting future climate projections in summer. Overall, the future scenario (ECHAM5 with A1B forcing) brings weak changes in mean precipitation, but stronger hourly intensities in the morning and less frequent but more intense daily precipitation. The two model simulations produce similar changes in climate, despite differences in their physical characteristics linked to the formation of convective precipitation. A significant increase in the morning precipitation
\end{abstract}

Electronic supplementary material The online version of this article (doi:10.1007/s00382-016-3186-4) contains supplementary material, which is available to authorized users.

G. Fosser

giorgia.fosser@metoffice.gov.uk

1 Institute of Meteorology and Climate Research (IMK-TRO), KIT, Hermann-von-Helmholtz Platz 1, 76344 Eggenstein-Leopoldshafen, Germany

2 CNRM-GAME, CNRS and Météo-France, 42 Avenue Gaspard Coriolis, Toulouse, France

3 Present Address: Met Office Hadley Centre, Fitzroy Road, Exeter EX1 3PB, UK

4 Hydrology Research Unit, Swedish Meteorological and Hydrological Institute, Folkborgsvägen 17, 60176 Norrköping, Sweden probably due to large-scale forced convection is found when considering only the most extreme events (above $50 \mathrm{~mm} /$ day). In this case, even the diurnal cycles of precipitation and convection-related indices are similar between resolutions, leading to the conclusion that the $7 \mathrm{~km}$ model sufficiently resolves the most extreme convective events. In this region and time periods, the $7 \mathrm{~km}$ resolution is deemed sufficient for most assessments of near future precipitation change. However, conclusions could be dependent on the characteristics of the region of investigation.

Keywords Regional climate model - Convectionpermitting resolution Climate change COSMO-CLM . Convection $\cdot$ Atmospheric processes

\section{Introduction}

Knowledge of the regional trends of the precipitation patterns under climate change is crucial to develop effective adaptation measures. Regional climate models (RCMs) help in bridging the gap between global climate models (GCMs) and regional planning requirements, and they provide the possibility for better insight into the future climate. Increasing horizontal resolution enables a more detailed representation of topographic features and leads to more realistic spatial patterns and intensity distributions of precipitation especially in terms of extreme events (Giorgi et al. 2004; Boberg et al. 2010). Recent assessments of changes in extreme short-term precipitation have indicated the added value of convective permitting RCMs, as opposed to the common parameterised coarser resolution RCMs (Kendon et al. 2014).

Independent of the spatial resolution, a strong consensus was reached on the future changes in temperature both 
over Europe and in southwestern Germany, which is the investigation area of this paper. A wide-spread increase is projected over the whole of Europe for all seasons with the largest warming in summer in the Mediterranean region (Christensen and Christensen 2007). In Germany, an annual increase of $\sim 1 \mathrm{~K}$ is projected for the next decades (Wagner et al. 2012). The climate change signal of temperature is mainly driven by the selected GCM and emission scenario used, while the role of RCMs becomes crucial when dealing with more complex processes such as precipitation, especially in summer when convection becomes dominant (Déqué et al. 2007; Wagner et al. 2012). Until the end of the century, RCMs project a general decrease in summer mean precipitation over western and southern Europe, which could be due to a northward deflection of Atlantic storms bringing wetter conditions to northern Europe (Christensen et al. 2007). Meanwhile, already for the end of the twentieth century Boberg et al. (2010) found a change in the probability density function (PDF) of simulated precipitation with increase in the more intense events and a decrease in light and moderate rain. For Germany, a similar trend is confirmed regarding the precipitation intensities for the near future (2021-2050; Wagner et al. 2012), while the decrease in mean precipitation is found not significant in summer. A consistent reduction in cloudiness, snow cover and soil water content is projected over Europe together with an increasing trend in atmospheric moisture, reaching $10-20 \%$ by the end of the century (Giorgi et al. 2004). For Germany, Feldmann et al. (2013) hypothesized that the changes in extreme precipitation found for the near future could be related to changes in the soil moisture, surface energy balance or atmospheric stability. For the same period, a rise of $\sim 20 \%$ on the annual scale in the number of dry days and dry periods is projected for southwestern Germany in line with the European trend (Wagner et al. 2012).

The choice of RCM becomes of crucial importance when investigating the climate change in summer when e.g. the parameterisation of convection can impact strongly on the results (Giorgi et al. 2004). The limitations of convection parameterised RCMs in the representation of the diurnal cycle of precipitation and the atmospheric conditions leading to convection are well-known and documented (e.g. Brockhaus et al. 2008; Baldauf et al. 2011; Fosser et al. 2015). Reaching convection-permitting resolutions allows not only to eliminate a major source of uncertainties and errors, but also to improve the representation of hourly precipitation intensity and spatial distribution (Prein et al. 2013; Fosser et al. 2015) as well as the representation of surface fluxes (Tölle et al. 2014).

At the moment only two studies (i.e. Kendon et al. 2014; Ban et al. 2015) investigated the climate change signal of precipitation statistics at daily and sub-daily time scale using long simulations at convection-permitting resolution, and they compared these projections with those from standard parameterised RCMs. However, the two papers disagree on the final conclusions. For southern UK Kendon et al. (2014) found that, while the models agreed on the climate change signal in winter, only the high resolution model detected future intensification of short-duration rain in summer. This investigation pointed out the parameterization of convection as responsible for the underestimation of the precipitation changes due to its deficiencies in the representation of convective events. The effects of this underestimation on the society could be enormous if, as Kendon et al. (2014) mention, the summer extreme events intensify above expectations from the Clausius-Clapeyron relation (Lenderink and van Meijgaard 2008; Berg et al. 2013). Ban et al. (2015) investigated climate change signals for the Alps region, and found that both daily and hourly precipitation extremes intensify according to the ClausiusClapeyron relation when considering all days, and that in general convection-permitting and coarser resolution agree on the magnitude of the changes. The disagreements indicate either a regionally dependent pattern of changes, or a model dependency of the results.

In the present study, we investigate differences in climate change signals for southwestern Germany until the mid-century between simulations from a convection-permitting model in contrast to a coarser parameterized RCM. Particular attention is put on the understanding of the processes leading to future changes in the precipitation field. We perform two sets of 30 year long simulations for the recent past and near future using COSMO-CLM (COnsortium for Small scale Modelling model-in CLimate Mode, here abbreviated CLM); one at $7 \mathrm{~km}$ (CLM7) horizontal resolution with parameterisation of convection, and one at convection-permitting resolution, namely at $2.8 \mathrm{~km}$ resolution (CLM2.8). Note that we chose to investigate the near future time period 2021-2050 since this is the typical planning horizon for most adaptation strategies, even though the climate change signals are likely weaker for this period. Section 2 presents the investigation area and the model simulations used to investigate the climate change signal. The method is explained in Sect. 3, while in Sect. 4 the results are discussed. Section 5 presents the main conclusions.

\section{Model simulations and investigation area}

The COSMO model is a non-hydrostatic local area model for weather predictions (Steppeler et al. 2003) adapted by the COSMO-CLM community to perform climatological simulations (Böhm et al. 2006). The setup used in this study (CLM version 4.8) is the same as in Fosser et al. (2015). Namely, a Runge-Kutta time-stepping scheme and the radiation scheme of Ritter and Geleyn (1992) called every 

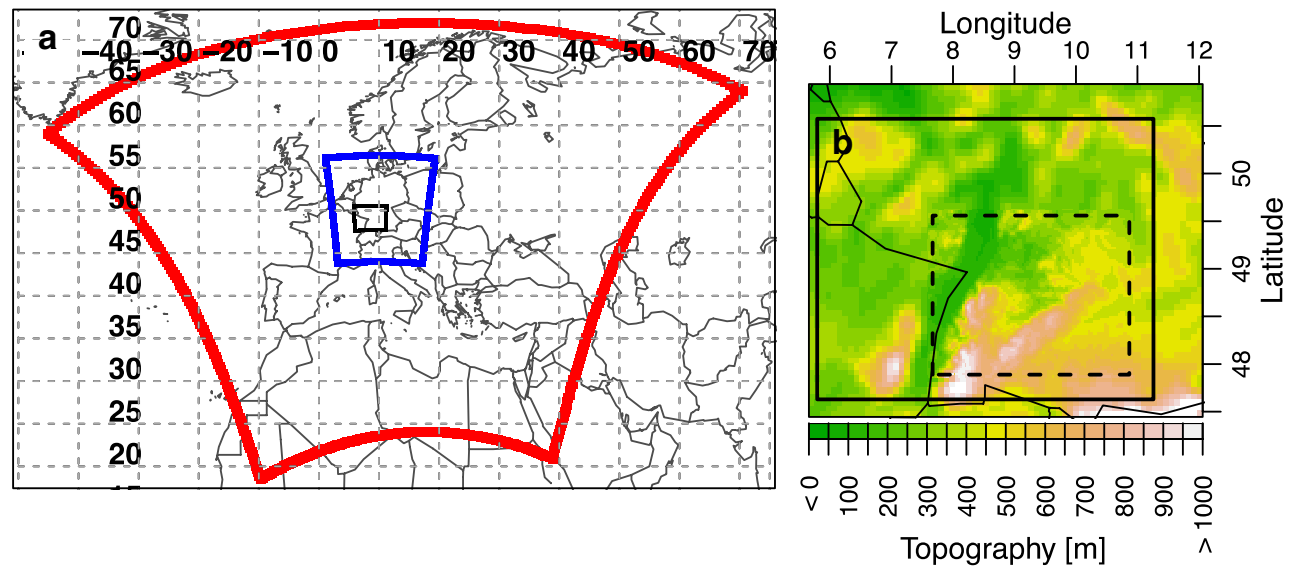

Fig. 1 a Simulation domain for each step of the nesting strategy, namely $50 \mathrm{~km}$ domain (red), $7 \mathrm{~km}$ (blue), $2.8 \mathrm{~km}$ (black). b Topographical features of the simulation domain at $2.8 \mathrm{~km}$ (solid box)

hour for CLM7, and every 15 min for CLM2.8. For CLM7 deep convection is parameterised following the Tiedtke (1989) scheme based on moisture convergence. Although the convection parameterisation leads to the misrepresentation of the diurnal cycle of precipitation (e.g. Brockhaus et al. 2008), a parameterisation for deep convection is still necessary at $7 \mathrm{~km}$ as shown by Fosser et al. (2015). Both CLM7 and CLM2.8 use the Tiedtke scheme for shallow convection. The Kessler scheme (Kessler 1995) is used for the calculation of grid scale clouds, and precipitation considers the following hydrometeor species: water vapour, cloud droplets, rain, snow, cloud ice, and for CLM2.8 additionally graupel. All simulations use 40 vertical levels and 9 soil layers. More details on CLM can be found in Doms et al. (2011).

To reach convection-permitting resolution a triple nesting procedure in rotated coordinates was applied (Fig. 1). The coarsest nest at $0.44^{\circ}$ resolution $(\sim 50 \mathrm{~km})$ comprises large parts of Europe $(118 \times 112$ grid points), while the next finer nest, CLM7, at $0.0625^{\circ}(\sim 7 \mathrm{~km})$ covers all of Germany and the near surroundings $(165 \times 200$ grid points). The finest nest, CLM2.8, at convection-permitting resolution, i.e. at $0.025^{\circ}(\sim 2.8 \mathrm{~km}, 140 \times 116$ grid points $)$, concentrates on the state of Baden-Württemberg in southwestern Germany. The coarser nest at $50 \mathrm{~km}$ resolution and CLM7 have already been validated and investigated in terms of climate change respectively by Berg et al. (2012) and Wagner et al. (2012). They found that the two resolutions perform similarly although added value for CLM7 was found in terms of spatial pattern and PDF of higher precipitation intensities.

The GCM ECHAM, used as driving model, was developed by the Max Planck Institute for Meteorology and it is one of the contributing models for AR4. Its fifth version, ECHAM5 (Roeckner et al. 2003), has been widely used for located in Baden-Wüttemberg in southwestern Germany. The black dashed-line box indicates the investigation area common to CLM7 and CLM2.8

studies on the climate change signal (e.g. Reichler and Kim 2008; Feldmann et al. 2013; Wagner et al. 2012). Here, for the recent past only twentieth century anthropogenic greenhouse gas forcing is considered (Roeckner et al. 2006), and for the future the IPCC SRES A1B forcing scenario is used (Nakicenovic et al. 2000). Note that for the selected future period, i.e. 2021-2050, the climate change signal is weaker than for the period 2071-2100 commonly used in climate change studies (Giorgi et al. 2004; Déqué et al. 2005; Christensen et al. 2007; Christensen and Christensen 2007; Déqué et al. 2007; Boberg et al. 2009). The downscaling is performed for two 33-year periods, and the first 3 years are considered spin-up time and therefore not included in the analysis. Thus, the two 30 year periods investigated are 1971-2000 for the past and 2021-2050 for the future. Berg et al. (2012) investigated three different realizations of the ECHAM5 model for the control period, and found limited differences in mean temperature and precipitation for central Europe, although realization one showed slightly higher probabilities for the most extreme precipitation events and is therefore selected for further downscaling here. Wagner et al. (2012) investigated the climate change of the three realizations and again found strong similarities between the realizations, with some minor spatial differences in the patterns.

The investigation area, located in the state of BadenWürttemberg in southwest Germany, was selected because of the distinct orographic features that make the region meteorologically interesting. Starting from the west, Fig. 1 shows the flat Rhine valley along the western edge of the investigation domain surrounded by the sharp orography of the Black Forest, with its two main ridges in a south-west to north-east direction. The complex terrain favours orographically induced convective precipitation, which dominates in the summer period in this region (Khodayar et al. 
2013). Fosser et al. (2015) found that CLM2.8 represents well the diurnal cycle of precipitation as well as the hourly precipitation intensities in this region and season.

\section{Methodology}

The aim of this paper is to compare the climate change signals from a long-term simulation at convection-permitting resolution with the projections obtained from a coarser parameterized model. Due to the different resolutions, the whole analysis is based on CLM2.8 bilinearly remapped to the same grid as CLM7. Tests were performed to check on the influence of different remapping techniques (e.g. conservative) and no substantial differences were found. Note that Fosser (2014) performed a similar analysis on the native grid (i.e. $2.8 \mathrm{~km}$ resolution) obtaining similar results for the precipitation statistics.

The GCM driven control simulation is not validated in this paper since the RCM itself was already investigated in Fosser et al. (2015) and the control period was validated for the period 1971-2000 in Fosser (2014). In particular, Fosser (2014) found that compared to ERA40 driven simulations, ECHAM5 driven simulations highly overestimate the number of wet days especially in winter, as also pointed out by Berg et al. (2012) and Feldmann et al. (2008). This leads to a strong overestimation in daily mean precipitation especially at coarser resolution. On daily basis, the probability distribution of precipitation intensities shows that the model is not sensitive to the change of the forcing in winter, while a slight underestimation of higher intensities can be found in summer for the $2.8 \mathrm{~km}$ resolution. The underestimation of higher precipitation intensities appears more marked on hourly basis especially in winter and at higher resolution (Fosser 2014).

The two ECHAM simulations share similar lateral boundary conditions, because CLM2.8 is nested in CLM7. This, in addition to the small size of the simulation domain, should lead to a similar representation of the large-scale events for both resolutions. Nevertheless, substantial differences in the representation of precipitation could appear when convection becomes dominant. In fact, the main difference between the two simulations is the treatment of deep convection, which is parameterized in CLM7 and explicitly resolved in CLM2.8. The weaknesses of CLM7 in the representation of convective processes and the consequent misrepresentation of the diurnal cycle of precipitation have been highlighted by Fosser et al. (2015). Moreover, convection-permitting resolution better represents regional and small-scale characteristics and spatial variability, which is highly relevant for convection (e.g. Weckwerth 2000). A better resolved topography could impact directly on the initiation of convection e.g. through an improved representation of secondary circulation systems which lead to convergence (e.g. Barthlott et al. 2006). The misrepresentation of convective processes at coarser resolution could thus lead for example to an underestimation of precipitation intensities also in the future scenario.

For both resolutions, first the precipitation projections in terms of spatial distribution and intensities are presented, followed by an analysis of convection-related parameters to assess the atmospheric conditions leading to precipitation. We expect the main changes being due to short extreme events related with convection, in line with previous literature (Kendon et al. 2014). Therefore, the analysis focuses on the summer season, June-July-August (JJA), when convection becomes dominant and the climate change signal is more pronounced (Giorgi et al. 2004). Although results on daily base are also presented, most of the attention is given to the sub-daily timescale where differences between the resolutions should become more evident (Kendon et al. 2014).

Bias maps and probability distribution plots as well as diurnal cycles are used to assess the differences between past and future in the precipitation pattern and related atmospheric fields. To estimate the statistical significance of the changes in the spatial distribution of precipitation, the Student's t test was applied, and the $95 \%$ confidence level is presented in the figures. In order to have independent datasets with the same variance, monthly means are used for the test. The autocorrelation of the monthly data was investigated to justify this choice. For the rest of the analysis, the $95 \%$ confidence intervals were calculated using the bootstrapping with replacement technique by Efron and Tibshirani (1993). In this case, the confidence intervals are calculated by randomly selecting 30 years between 1971 and 2000 a large number of times (i.e. 1000 surrogates in this work) and multiplying their standard deviation by 1.64485 .

The main ingredients required for the occurrence of deep convection are, besides a moist atmosphere, the presence of an unstable atmosphere and a trigger mechanism allowing the release of the convective available energy (Johns and Doswell 1992; Khodayar et al. 2010, 2013). The vertical velocity at different atmospheric levels, $950 \mathrm{hPa}$ and $500 \mathrm{hPa}$, is used to evaluate the vertical motion in the low atmosphere and upper troposphere, respectively.

The following convection-related indices, namely the convective available potential energy (CAPE; Moncrieff and Miller 1976) and the KO-index (Andersson et al. 1989), are used as indicators of the atmospheric stability conditions, and thus of the atmospheric predisposition to convection and consequent heavy precipitation. Based on the temperature and moisture of the ascending parcel, the CLM model computes CAPE in each grid point. The model initialises the rising parcel using the mean state of 
the lowest $50 \mathrm{hPa}(50 \mathrm{hPa}$ mixed layer method). In the diurnal cycle, calculated over 30-years simulations, we expect higher CAPE values ahead of the maximum precipitation in the afternoon when convection becomes predominant. The PDF of CAPE allows assessing the intensity ranges in which the main changes take place. CAPE is strongly correlated to the atmospheric conditions in the lower boundary layer (Khodayar et al. 2013), thus it generally adequately represents latent instability conditions prior to deep convection forced by boundary layer. The vertical velocity at $950 \mathrm{hPa}$ is used to evaluate the vertical motion in the low atmosphere. Khodayar (2009; Khodayar et al. 2014) pointed out that atmospheric instability associated to deep convection triggered by large-scale forcing is better represented by the KO-index. The KO-index illustrates the modification in the atmospheric potential instability. It uses conditions at different levels of the atmosphere, rather than conditions in the lower boundary layer such as CAPE to infer stability conditions. The KO-index is computed based on the equivalent potential temperature, $\theta$, at 500, 700, 850 and $1000 \mathrm{hPa}$ (following the recommendations by Bolton 1980) as follow:

$$
K O=0.5\left(\theta_{700}+\theta_{500}-\theta_{1000}-\theta_{850}\right)
$$

Differences in the distribution and intensity of the KOindex and in the vertical motion field at $500 \mathrm{hPa}$, i.e. presence or not of large-scale lifting, determine favourable or unfavourable atmospheric conditions for deep convection. General notation identifies regions with KO-index $<2 \mathrm{~K}$ and large-scale lifting as favourable for deep convection. Both the selected convection-related indices depend on temperature and specific humidity and their distribution (Emanuel 1994). Future changes in temperature and humidity are likely to be linked and to directly or indirectly affect several atmospheric fields such as cloud cover, radiation and fluxes. Those fields are also investigated and the main results reported.

\section{Results}

\subsection{Precipitation statistics}

The convection permitting scale simulation, CLM2.8, projects a decrease in JJA for the daily mean precipitation over most of the investigation area, with maximum of $\sim 15 \%$ over the northwestern ridge of the Black Forest (Fig. 2 top). The coarser resolution, CLM7, provides a similar picture. However, the significance test shows that these changes are not robust, with less than $3 \%$ (15\%) of the grid points above the $90 \%$ level for CLM2.8 (CLM7). Analysis performed for the Wagner et al. (2012) paper (personal communication) shows similar decreases in mean precipitation in JJA for all three realizations of ECHAM5 downscaled by CLM7, and cases of increases in precipitation seems to be more related to natural variability than a result of climate change. Notice that those differences in the precipitation pattern related to the complex orography are not seen in Ban et al. (2015), who with a similar model showed consistently decreasing intensities for the current domain.

The number of dry days, defined as days with less than $1 \mathrm{~mm}$ of precipitation, differs substantially between the two resolutions, with CLM2.8 being drier than CLM7 (Table 1). Fosser et al. (2015) showed that CLM2.8 agrees well with observations in terms of sub-daily precipitation statistics, while CLM7 is too wet as a consequence of too frequent drizzle. The use of ECHAM at the lateral boundary compared to using ERA40 (in Fosser et al. (2015)) leads to a decrease in the percentage of dry days, especially for CLM2.8. The future projections results show increases in the percentage of dry days by $4 \%$ and $5 \%$ for CLM 2.8 and CLM7, respectively (Table 1). For both resolutions, the increase is almost homogeneous over the investigation area (not shown).

When only considering wet days, there is a clear increase in the average intensity of precipitation for most of the domain, however, only significant for lower elevation regions where the signal is also stronger (Fig. 2 middle). Thus, the removal of the dry days leads to a constant shift of the mean toward wetter conditions and even to a change in the sign over the crests, which means that while the days with precipitation decrease, the intensities are higher when it does rain. Both resolutions project an increase up to $20 \%$ in the mean wet day precipitation over the area but with differences in the spatial pattern. In particular, CLM2.8 tends to localise the maximum changes between the two main ridges of the Black Forest while for CLM7 the maximum occurs southeast of the second ridge (south-east of the investigation domain in Fig. 2 middle). The differences in the spatial pattern between resolutions are probably linked to the better resolved orography in CLM2.8, which allows accounting for small-scale processes related with orographic features, such as orographically-induced wind circulations and upward motion over the mountains which could favour convective initiation.

The CLM model tends to locate the most intense precipitation over the western windward side of the first ridge of the Black Forest (Khodayar et al. 2013) and the same pattern will be maintained in the future (not shown). To evaluate any possible future shift in the location of intense precipitation, we selected, from both CLM7 and CLM2.8 remapped at $7 \mathrm{~km}$, the very heavy precipitation days, defined as days with precipitation above $20 \mathrm{~mm} /$ day (Klein Tank et al. 2009). Figure 2 bottom shows the mean precipitation calculated for those days and the significance of the changes. The significance is very low for these extreme 

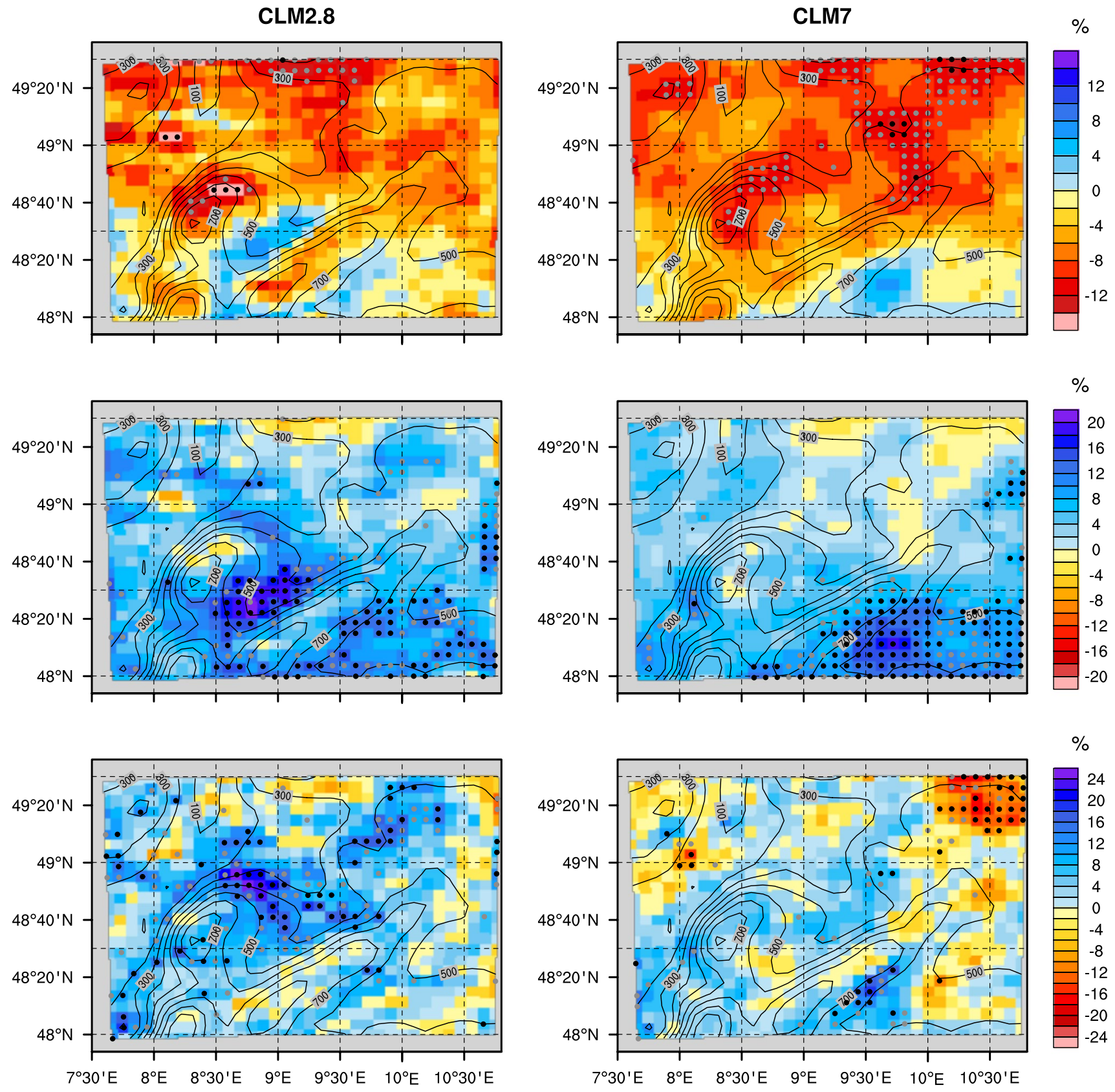

Fig. 2 Spatial distribution of the projected changes in daily mean precipitation calculated for all days (top), only wet days (middle) and for very heavy precipitation days, defined as days with precipitation above $20 \mathrm{~mm} /$ day (Klein Tank et al. 2009), (bottom) for $2.8 \mathrm{~km}$ (left)

Table 1 Percentage of dry days $(<1 \mathrm{~mm} /$ day $)$ and dry hours $(<0.1 \mathrm{~mm} / \mathrm{h})$ for 2.8 and $7 \mathrm{~km}$ resolution in the past and future

\begin{tabular}{llllll}
\hline & \multicolumn{2}{l}{ Dry days (\%) } & & \multicolumn{2}{c}{ Dry hours $(\%)$} \\
\cline { 2 - 3 } \cline { 6 - 7 } & $2.8 \mathrm{~km}$ & $7 \mathrm{~km}$ & & $2.8 \mathrm{~km}$ & $7 \mathrm{~km}$ \\
\hline Past & 60 & 51 & 85 & 82 \\
Future & 64 & 56 & 87 & 84 \\
Difference & 4 & 5 & 2 & 2 \\
\hline
\end{tabular}

and $7 \mathrm{~km}$ (right) resolution in JJA. The contours indicate the topography (in m). Gray (black) dots represent significance above the $90 \%$ $(95 \%)$ level

intensities, and even at the $90 \%$ level only $15 \%$ of the grid points shows significant changes for CLM2.8, and for CLM7 only $9 \%$. There is furthermore no consistency between the grid points that pass the significance test for the two simulations, although the pattern as a whole is rather similar. The CLM2.8 simulation projects higher increase in the plain area north of the first ridge expanding up to the second ridge. These changes, especially for CLM2.8, are linked to an increase in frequency and intensity of the most 
Fig. 3 IDF of precipitation intensities above $1 \mathrm{~mm} /$ day $(0.1 \mathrm{~mm} / \mathrm{h})$ for daily (hourly) temporal on the left (right) for JJA. Dots indicate the bin centres. Note the logarithmic vertical axis. The dashed lines indicate the $95 \%$ confidence intervals calculated with a bootstrapping technique
Fig. 4 IDF for different time periods of the day of precipitation intensities above $0.1 \mathrm{~mm} / \mathrm{h}$ for hour temporal resolution for JJA. Note the logarithmic vertical axis. The dashed lines indicate the $95 \%$ confidence intervals calculated with a bootstrapping technique
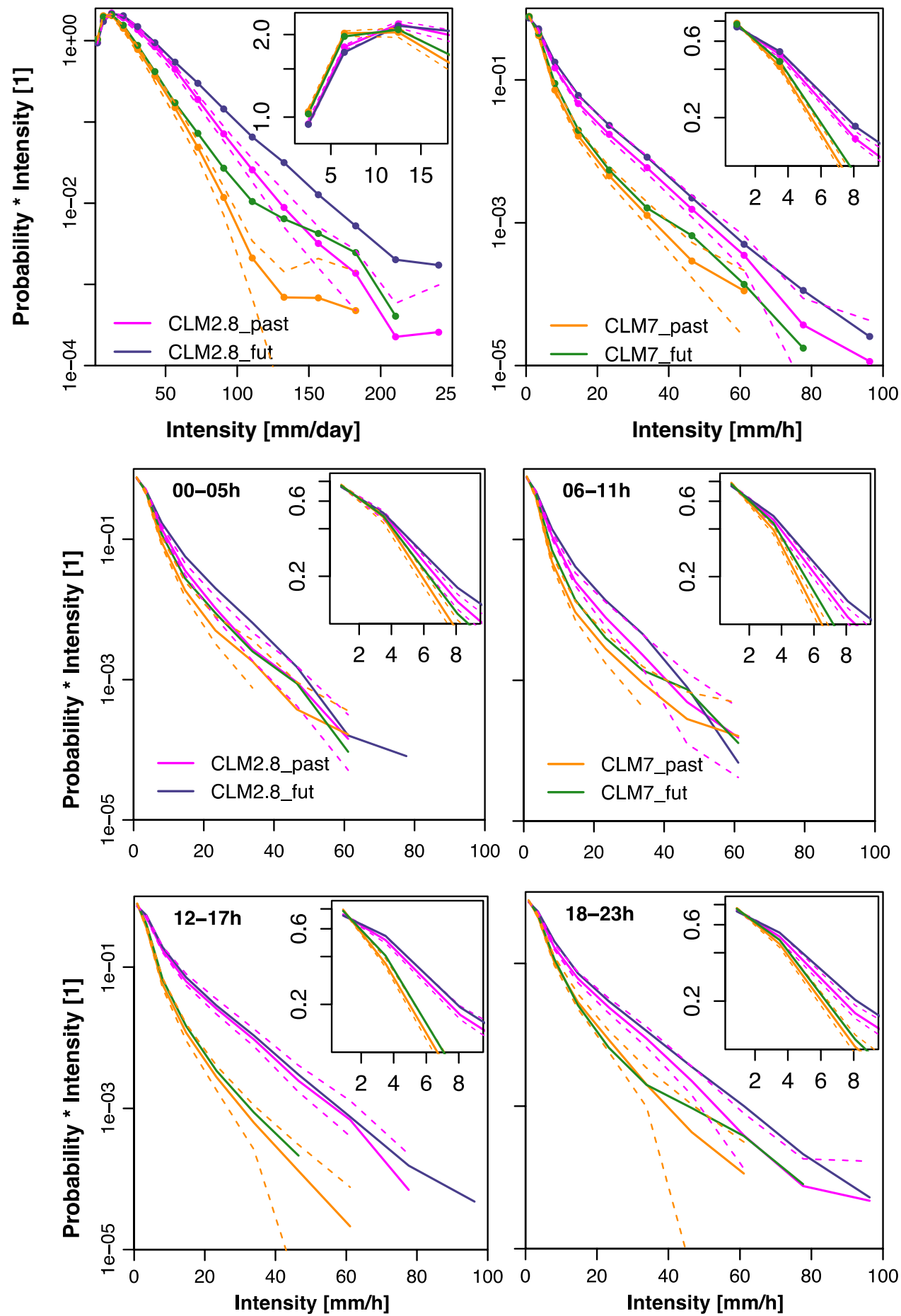

extreme precipitation, i.e. precipitation above $50 \mathrm{~mm} /$ day, over the same areas (not shown). However, the results can hardly be considered significant for either simulation.

\subsubsection{Precipitation intensities}

The increased percentage of dry days and dry hours (Table 1) strongly impacts the distribution of precipitation intensities, thus in the following we focus only on wet days and hours. Fig. S1 and Fig. S2 in the supplementary material show the same figures as Fig. 3 and Fig. 4 but for all days and hours. The following intensity distribution functions, called IDF, are weighted by the intensity (i.e. the probability of the precipitation intensity of each bin is multiplied by the intensity of the bin). To make the message clearer from the graph, the bins are not of equal size, but 

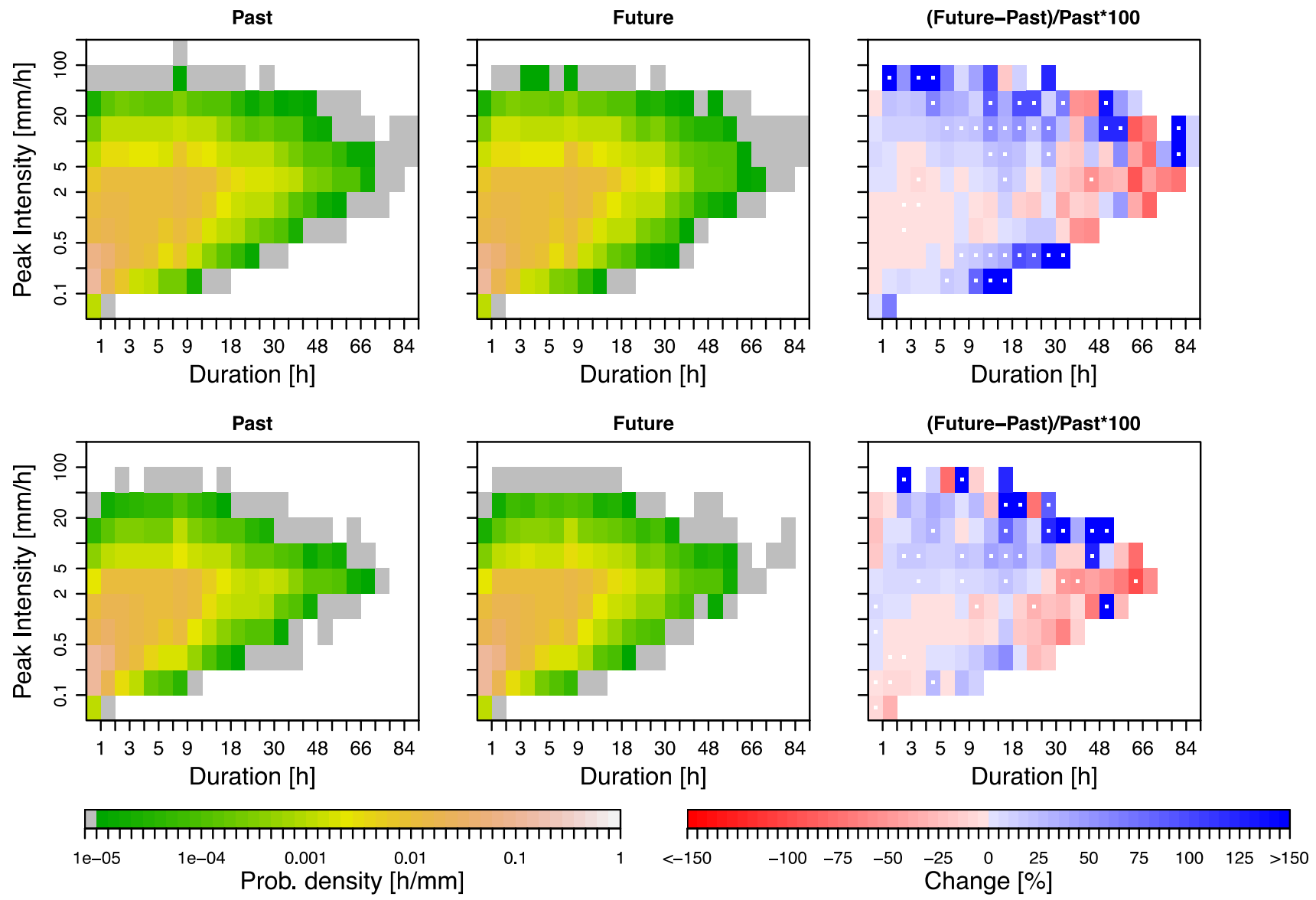

Fig. 5 Peak event intensity in JJA as a function of event duration for CLM2.8 (top) and CLM7 (bottom). The white dots indicate significant changes at the $95 \%$ level

the results hold even using equally spaced bins (not shown). For ease of reference we term IDF values probabilities.

The IDF of daily precipitation intensities shifts toward higher intensities at the cost of the lower intensities between the control and scenario time periods for both resolutions (Fig. 3 left). In particular, there is a significant decrease in the probability of precipitation intensities between 5 and $10 \mathrm{~mm} /$ day ( 3 and $7 \mathrm{~mm} /$ day) as well as a significant increase for precipitation intensities above $50 \mathrm{~mm} /$ day $(70 \mathrm{~mm} /$ day) for CLM2.8 (CLM7). Similar results are qualitatively similar when all days are included (S. 1). The results are better represented in aggregated statistics, compared to the spatially resolved information in the previous section.

On hourly resolution, the IDF shows an increased probability of precipitation intensities above about $2 \mathrm{~mm} / \mathrm{h}$ for both simulations but stronger for CLM2.8 (Fig. 3 right). Although the change is consistent for the whole intensity range above $2 \mathrm{~mm} / \mathrm{h}$, the confidence interval indicates that the change is not statistically significant. The offset between resolutions at both daily and hourly base is the same as in Fosser et al. (2015) and it is not related to the forcing used but rather to the characteristics of the two models. Again, the conclusions remain valid also when all hours are included (S. 1).

Subdividing the data in four selected time periods of the day (Fig. 4 and S. 2), it becomes clear that the increase in the hourly IDFs is mostly due to precipitation in the night to morning hours period (00-12). Although the most intense events will occur in the afternoon also for the future, there are no significant changes in the IDF at this time of the day. The two resolutions agree on the sign of the projected changes.

\subsubsection{Structure of the precipitation events}

Similarly to Kendon et al. (2014), we investigate the duration-intensity characteristics of rainfall. An event is here defined as continuous precipitation above $0.1 \mathrm{~mm} / \mathrm{h}$ and the analysis is performed for both peak (Fig. 5) and average intensities (S. 3) of each duration bin. The event statistics for CLM2.8 show that the shortest high-intensity events (i.e. $1-3 \mathrm{~h}$ for $50-100 \mathrm{~mm} / \mathrm{h}$ ), which are probably due to convection, are projected to increase in both peak 
Fig. 6 On the left, PDF of IWV for the JJA period; note the logarithmic vertical axis. On the right, diurnal cycle of total (CLCT), medium (CLCM) and low (CLCL) cloud cover. The coloured sections indicate the $95 \%$ confidence intervals calculated with a bootstrapping technique
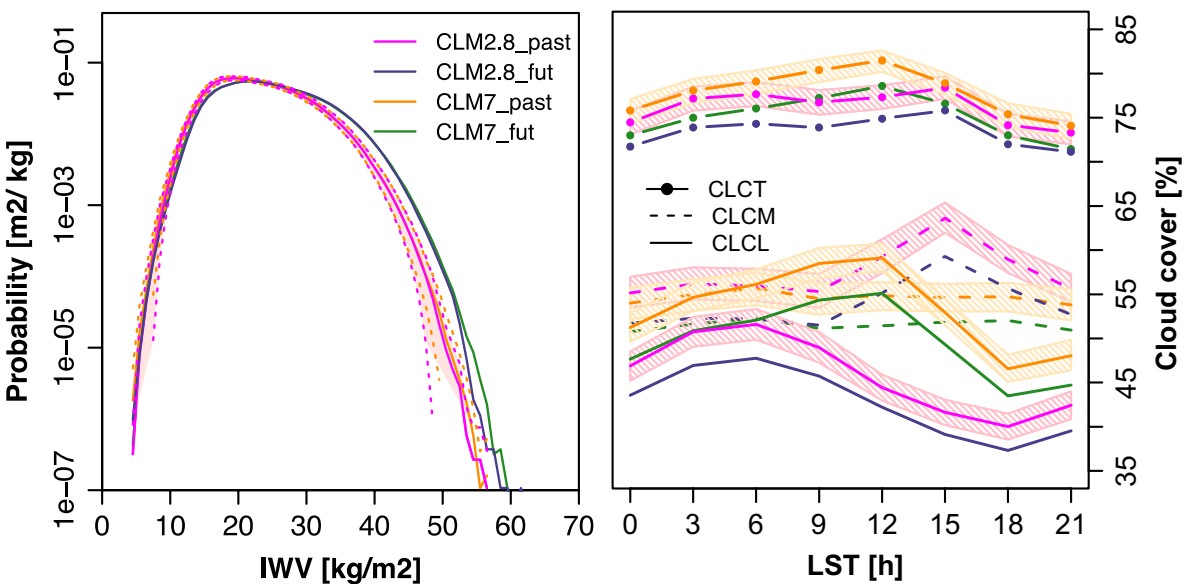

(Fig. 5) and average intensity (S. 3) by more than $100 \%$. This change is accompanied by an increased intensity also for longer events $(5-30 \mathrm{~h}$, intensity above $10 \mathrm{~mm} / \mathrm{h}$ ) likely related to stratiform precipitation. The increases are stronger than those found in Kendon et al. (2014). The frequency of low-intensity events $(0.5-5 \mathrm{~mm} / \mathrm{h})$ with a duration below $7 \mathrm{~h}$, or longer than $30 \mathrm{~h}$ seems to decrease in line with the increase of both the percentage of dry hours (Table 1) and the length and the frequency of dry periods, defined as at least five consecutive dry days (not shown). CLM2.8 also projects an increase of events between 0.1 and $0.25 \mathrm{~mm} / \mathrm{h}$ with duration between 9 and $30 \mathrm{~h}$. These events could be a combination of stratiform rain and drizzle, which affects especially this resolution, creating too long events of overestimated amount (Fosser et al. 2015). Surprisingly, CLM7 shows similar signals, besides slightly underestimating the more intense events, i.e. intensities above $20 \mathrm{~mm} / \mathrm{h}$. The agreement in signals between CLM2.8 and CLM7 is in contrast with the deficiencies of the parameterised-convection model used by Kendon et al. (2014) that was not able to represent the changes of more extreme precipitation. This disagreement between models could be linked to the relatively high resolution of CLM7 that probably allows better resolving the larger convective systems, compared to the coarser $12 \mathrm{~km}$ MetUM model.

\subsection{Atmospheric conditions leading to convective precipitation}

The analysis in the previous sections showed that the simulated future changes in precipitation affect mainly short events with high intensity (Fig. 5), which are usually of convective nature, but also the morning precipitation that is mostly linked with large-scale processes. The purpose of this section is to assess some of the atmospheric conditions that could explain the aforementioned changes in the precipitation field.
At both resolutions, a shift of $\sim 1 \mathrm{~K}$ toward higher values is projected for atmospheric temperature at all atmospheric levels (S. 4) in the near future, in line with previous findings for surface temperature over Germany (Wagner et al. 2012). Both resolutions project an increase in mean integrated water vapour (IWV) of $\sim 2 \mathrm{~kg} / \mathrm{m}^{2}$ (not shown). This increase affects mainly the lower atmospheric levels (below $850 \mathrm{hPa}$ ) where an increase of about $0.5 \mathrm{~g} / \mathrm{kg}$ in specific humidity is identified (S. 4). Besides the change in mean IWV, also its PDF is shifted so that there is an increased probability of IWV values above $35 \mathrm{~kg} / \mathrm{m} 2$ and a slight decrease for lower values (i.e. $15-25 \mathrm{~kg} / \mathrm{m}^{2}$; Fig. 6 left). Note that a similar PDF is found for all four time periods of the day (S. 5). Moreover, considering days with precipitation above $50 \mathrm{~mm} /$ day, the shift towards higher IWV at the cost of the lower values becomes even more pronounced (S. 6).

Observational studies indicate changes in convective precipitation beyond the $7 \% / \mathrm{K}$ Clausius-Clapeyron rate (CC-rate; e.g. Trenberth et al. 2003), or rather a super-CCrate (Lenderink and van Meijgaard 2008; Berg et al. 2013; Westra et al. 2014). When comparing historical to end of century projections in the RCP8.5 scenario, Ban et al. (2015) found an intensification of the extremes according to the standard CC-rate over the Alps and surrounding regions, while for the southern UK, Kendon et al. (2014) found that the increase in convective precipitation was consistent with a super-CC-rate. The scaling between precipitation intensity and temperature is strongly affected by the inclusion or not of dry days in the calculation of the extreme percentiles (Ban et al. 2015). According to Chan et al. (2015), future CC-scaling rate might be different compared to present observed scaling for southern UK when the changes in the large-scale weather pattern modify moisture availability. In the CLM7 and CLM2.8 simulations, when all days are considered, even the 99.9th percentile scales well below the CC-rate, and the 95th percentile shows negative scaling (Table 2). When only wet days are considered, i.e. a wet 
Table 2 Scaling of different percentiles of hourly precipitation intensity with the change in domain average temperature between the control and scenario periods

\begin{tabular}{|c|c|c|c|c|c|c|}
\hline \multirow{3}{*}{$\begin{array}{l}\text { Precipitation } \\
\text { Temperature } \\
\text { Quantile }\end{array}$} & \multirow{2}{*}{\multicolumn{2}{|c|}{$\frac{\text { All days }}{\text { All days }}$}} & \multirow{2}{*}{\multicolumn{2}{|c|}{$\frac{\text { Wet days }}{\text { All days }}$}} & \multirow{2}{*}{\multicolumn{2}{|c|}{$\frac{\text { Wet days }}{\text { Wet days }}$}} \\
\hline & & & & & & \\
\hline & $2.8 \mathrm{~km}$ & $7 \mathrm{~km}$ & $2.8 \mathrm{~km}$ & $7 \mathrm{~km}$ & $2.8 \mathrm{~km}$ & $7 \mathrm{~km}$ \\
\hline 95 & -7.6 & -5 & 5.8 & 4.5 & 8.3 & 5.8 \\
\hline 99 & 1.5 & 1.5 & 8.5 & 6.7 & 12.1 & 8.7 \\
\hline 99.9 & 5.2 & 3.2 & 9.8 & 6.7 & 13.7 & 8.3 \\
\hline
\end{tabular}

Units are in $\% / \mathrm{K}$ hour limit of $1 / 24 \mathrm{~mm} / \mathrm{h}$, and temperature differences are calculated for all days, the scaling rate increases to close to the CC-rate for CLM7, and even beyond that for CLM2.8 for the 99th and 99.9th percentiles. However, as the scaling of extreme precipitation should be compared to the air mass close to the time of precipitation, a better measure of the scaling is performed for wet days both for precipitation and temperature. This measure increases the scaling rates further, with CLM2.8 being close to a two times the CC-rate for the highest percentiles, while CLM7 remains close to or slightly above the CC-rate.

Changes in temperature and specific humidity are likely to indirectly affect also the cloud cover (e.g. Jaeger et al. 2008). The simulations project a significant decrease by almost $5 \%$ in total cloud cover, especially in the morning, linked with a decrease at low and medium levels (Fig. 6 right). Note that the differences between CLM2.8 and CLM7 are the same as seen in Fosser et al. (2015), and are thus attributable to the model resolution and use, or not, of the convection parameterisation rather than to the lateral forcing. This result is in line with findings by Giorgi et al. (2004) over central Europe at the end of the century. In particular, they found a uniform reduction in cloudiness, despite an increase of 10-20\% in atmospheric moisture. Our investigation reveals that the decrease in cloud cover occurs during dry days, In fact, considering only wet days, cloud cover experience an increase by almost $5 \%$ in high level clouds that despite the decrease of low level clouds leads to a slight increase in total cloud cover (S. 7).

\subsection{Diurnal cycle of precipitation and convection-related parameters}

So far, we have only identified minor differences between the two simulations, CLM7 and CLM2.8. Fosser et al. (2015) found significant differences in the diurnal cycle of precipitation intensity, with CLM2.8 being closer to observations, and showing a consistent response of the convective precipitation to CAPE. Meanwhile, precipitation in CLM7 was shown to be disconnected from the atmospheric conditions leading to convection, e.g. the diurnal cycle of CAPE, and presented a premature precipitation peak. Here, we investigate whether the improved physical consistency in CLM2.8 compared to CLM7 leads to significant differences in the projected changes in precipitation.

In the following, the diurnal cycles of precipitation, convection-related indices previously described (Sect. 3), namely CAPE and KO-index, and vertical velocities (at 500 and $950 \mathrm{hPa}$ ) are discussed depending on the daily precipitation threshold selected. The diurnal cycles of each variable are calculated as a spatial mean based on the grid points where the daily precipitation is above the selected threshold. The thresholds used are: $0 \mathrm{~mm} /$ day i.e. all days; $1 \mathrm{~mm} /$ day, corresponding to the definition of wet day; and $50 \mathrm{~mm} /$ day threshold here considered as a threshold for extreme precipitation events. Note that above the latter threshold the projected changes in the daily IDF become significant for CLM2.8 (Fig. 3 left). It is worth mentioning that the number of days with precipitation above $50 \mathrm{~mm}$ are more than double for CLM2.8 compared to CLM7 (479 versus 213 events) while almost no differences are found between past and future (e.g. 479 in the past versus 495 in the future for CLM2.8). This large difference between resolutions results in a broader confidence interval for CLM7 compared to CLM2.8 (see shaded area in Fig. 10).

Each of the following subsections outlines the main impacts of using different thresholds on the historical runs and then investigates the climate change signal for both resolutions.

\subsubsection{Diurnal cycles considering all days}

When considering all days (Fig. 7), the diurnal cycle of both precipitation and CAPE for either resolutions are consistent with previous findings by Fosser et al. (2015; see also chapter 4.3). This shows that the expected relationship between the atmospheric instability maximum and consequent convective precipitation occurrence is maintained only when convection is not parameterised, and it is not sensitive to the forcing used. The KO-index values close to $-2 \mathrm{~K}$ from about 15:00 are likely indicative of a potentially unstable atmosphere prone to deep convection under the presence of large-scale forcing (i.e. maximum vertical velocity at $500 \mathrm{hPa}$ at the same time). 

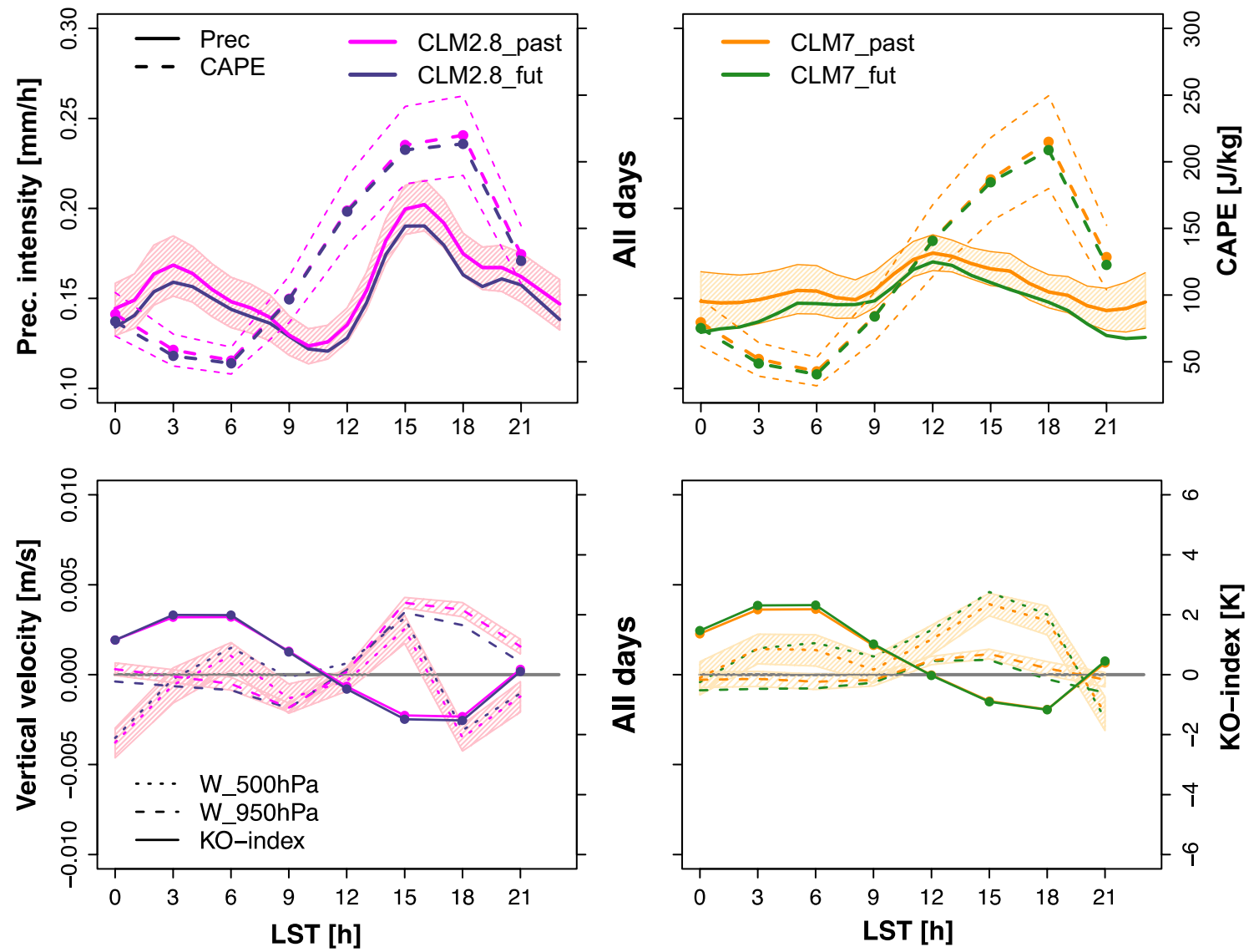

Fig. 7 Diurnal cycle of (top) precipitation and CAPE, (bottom) KOindex and vertical velocity at 500 and $950 \mathrm{hPa}$, for CLM2.8 (left) and CLM7 (right) calculated considering all days in JJA. Dashed lines in the top row and shaded areas indicate the $95 \%$ confidence interval,

Therefore, the occurrence in CLM2.8 of events with higher intensity in the afternoon could be linked to the significantly more unstable atmosphere in this period, both latent and potential (i.e. higher CAPE and lower KO-index), in conjunction with a favourable large-scale environment. Although CLM7 shows a similar potential instability as CLM2.8 and higher values of vertical velocity at $500 \mathrm{hPa}$ between 15:00 and 18:00, convective precipitation does not occur at this time (Fosser et al. 2015).

In the future for both resolutions, the shape of the diurnal cycle of precipitation does not change significantly besides a general offset due to the decrease in average intensity or to an increase in the percentage of dry hours (Table 1). The decrease in precipitation in the afternoon could be partially explained by the reduction in boundary layer forced convection given the slight but significant decrease in vertical velocity at $950 \mathrm{hPa}$, especially for CLM2.8, in combination with no significant changes in CAPE (nor in KO-index and vertical velocity at $500 \mathrm{hPa}$ ). whereas the gray line shows the zero value for the vertical velocities. Note that the model outputs precipitation every hour while the other variables every $3 \mathrm{~h}$

\subsubsection{Diurnal cycles considering only wet days}

To consider only wet days does not significantly affect the shape of the diurnal cycle of precipitation in the past for either resolution, besides a general increase in the precipitation intensities due to the removal of the dry hours (Fig. 8 top). For CLM2.8, CAPE shows similar behaviour as in the case of all days until 15:00 (Figs. 7, 8 top) when it decreases sharply. The removal of dry days probably excludes those situations in which high values of CAPE do not lead to convective precipitation, resulting in the differences in the diurnal cycle of CAPE in the two cases (all day vs. wet days). CLM7 shows a diurnal cycle of CAPE very similar to CLM2.8, while it is still not able to correctly simulate the diurnal cycle of precipitation thus confirming that its inability is not directly linked to drizzle. Compared to the all days case, both resolutions show a more stable atmosphere (i.e. more positive KO-index) and more intense updrafts (i.e. higher vertical velocity at $500 \mathrm{hPa}$ ).

For the future, the shapes of the wet day diurnal cycles of precipitation are mostly retained at both resolutions but 

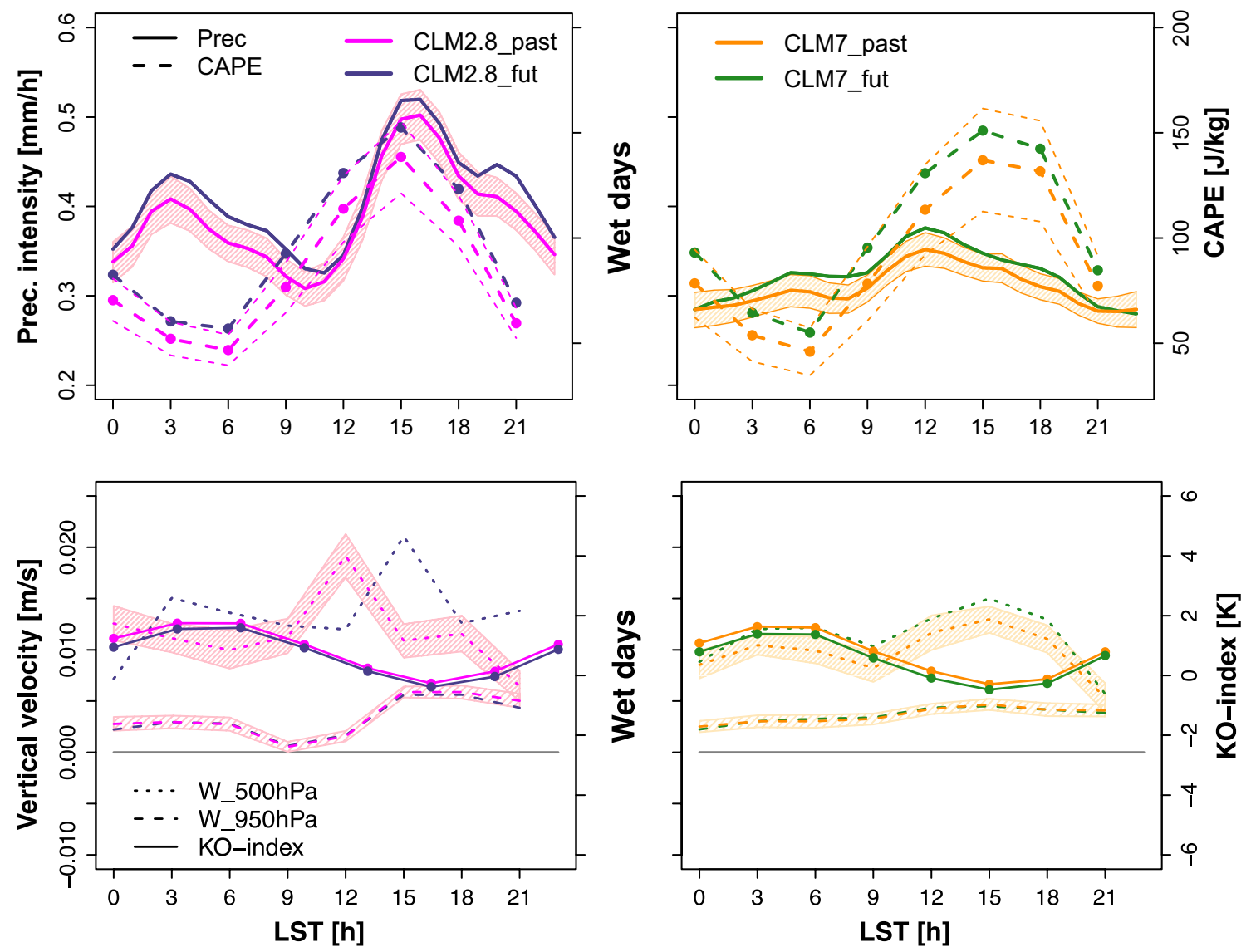

Fig. 8 Diurnal cycle of (top) precipitation and CAPE, (bottom) KOindex and vertical velocity at 500 and $950 \mathrm{hPa}$, for CLM2.8 (left) and CLM7 (right) calculated considering only wet days in JJA. Dashed lines in the top row and shaded areas indicate the $95 \%$ confidence

shifted toward higher values (Fig. 8 top) in line with the increase of mean wet precipitation (Fig. 2 middle) and the precipitation IDF at sub-daily resolution (Fig. 4).

The increase in the precipitation diurnal cycle could be linked with an almost homogeneous shift of CAPE toward higher values (dashed lines in Fig. 8 top). In particular, the occurrence of low to medium intensity precipitation events seems to be favoured in the morning, especially between 00:00 and 05:00, given the projected higher probability of CAPE between 200 and $1000 \mathrm{~J} / \mathrm{kg}$ in the same time period (Fig. 9 left). In the time interval 12:0017:00 (Fig. 9 right), the projected increase in CAPE is reaching more than $2000 \mathrm{~J} / \mathrm{kg}$, which could favour heavier precipitation events seen for CLM2.8 in Fig. 4 (bottom left). Similar signals, but not significant, are also found for CLM7 (S. 8).

The increase in the afternoon precipitation in CLM2.8 could also be driven by deep convection forced by largescale processes. In fact, CLM2.8 projects a time shift of the afternoon peak for the vertical velocity at $500 \mathrm{hPa}$, which coincides with the minimum of KO-index (Fig. 8 bottom), interval, whereas the gray line shows the zero value for the vertical velocities. Note that the model outputs precipitation every hour while the other variables every $3 \mathrm{~h}$

thus creating favourable atmospheric conditions for the initiation of deep convection. Also CLM7 shows an intensification of vertical velocity at $500 \mathrm{hPa}$ at the same time of maximum potential instability (i.e. 15:00), but this does not match with the maximum precipitation at 12:00.

\subsubsection{Diurnal cycles considering days with precipitation above $50 \mathrm{~mm}$}

Considering a threshold of $50 \mathrm{~mm} /$ day, and comparing on equal CLM7 resolution, leads to important changes for both resolutions and reveals interesting findings (Fig. 10). For CLM2.8, the diurnal cycle of precipitation shows the afternoon maximum occurring one hour later (at 16:00) and lasting longer compared to the previous cases. The diurnal cycle of CAPE does not change in shape but the mean values are much higher compared to the previous cases especially between 12:00 and 15:00 thus underlining the important role of the intense afternoon convective precipitation in days with precipitation above $50 \mathrm{~mm} /$ day. CAPE shows also high values at midnight to then sharply decrease, 
Fig. 9 PDF of CAPE for wet days and time period $00-05$ (left) and 12-17 (right) for CLM2.8 in JJA. Note the logarithmic vertical axis. The dashed lines and shaded areas indicate the $95 \%$ confidence intervals calculated with a bootstrapping technique
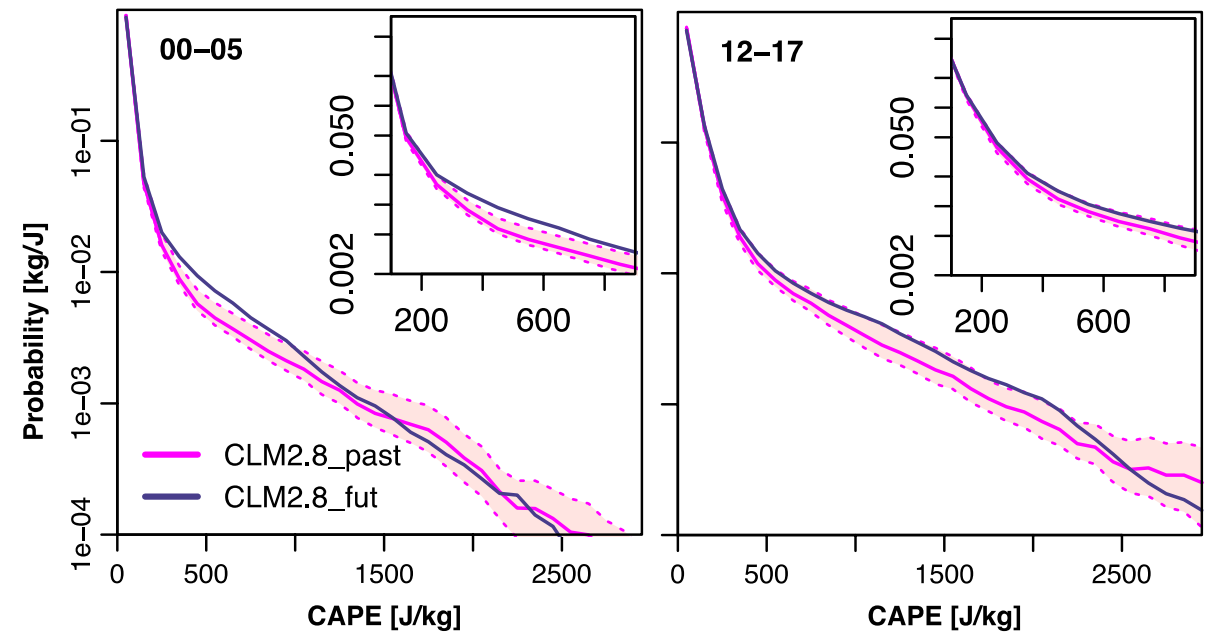
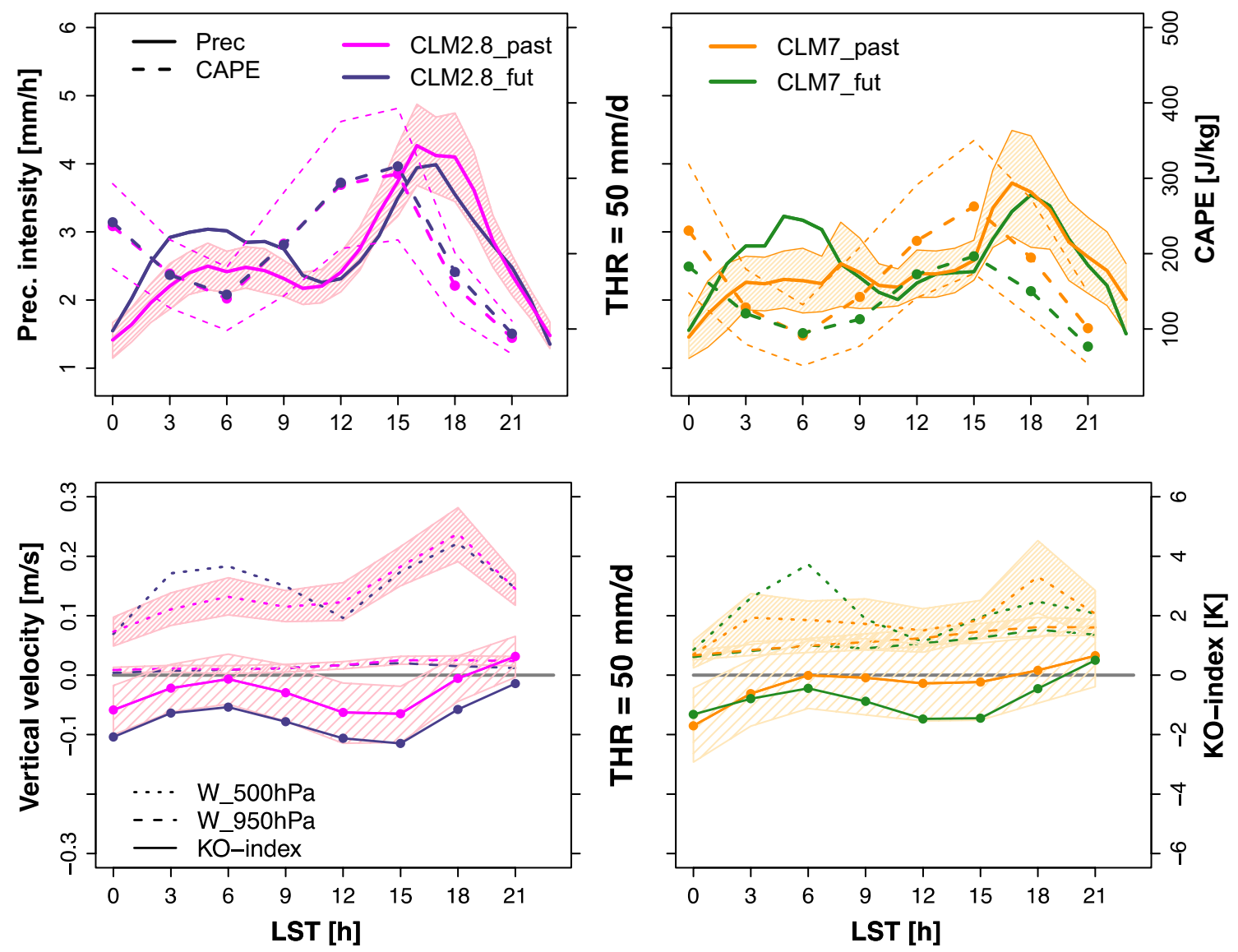

Fig. 10 Diurnal cycle of (top) precipitation and CAPE, (bottom) KO-index and vertical velocity at 500 and $950 \mathrm{hPa}$, for CLM2.8 (left) and CLM7 (right) calculated considering only days with precipitation above $50 \mathrm{~mm} /$ day in JJA. Dashed lines in the top row and shaded

areas indicate the $95 \%$ confidence interval, whereas the gray line shows the zero value for the vertical velocities. Note that the model outputs precipitation every hour while the other variables every $3 \mathrm{~h}$

and CAPE that become similar to those at CLM2.8 resolution, although with lower mean values. These changes for CLM7 are probably linked to large convective events that are at least partly resolved at the $7 \mathrm{~km}$ resolution. However,

Imposing such a high threshold for CLM7 leads to important changes in the diurnal cycles of both precipitation 
Fig. 11 Scatter plot of precipitation intensities for all grid points and hours of the 100 days with the most intense hourly precipitation intensities in JJA for CLM2.8 and CLM7 for daily (left) and hourly (right) value sorted in ascending order

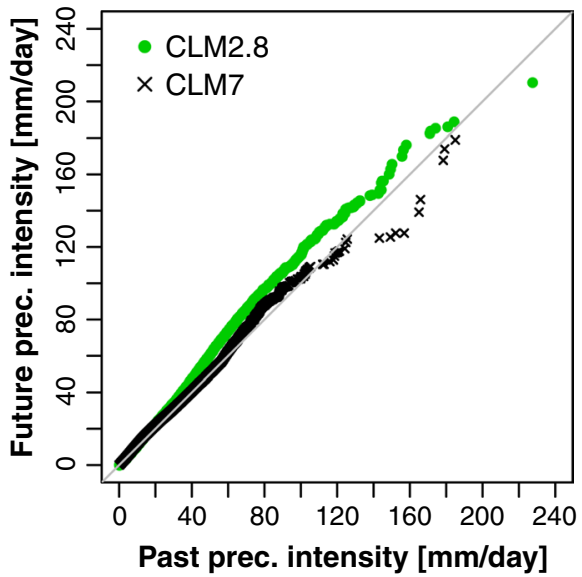

it is interesting to note that even with a lower threshold of $20 \mathrm{~mm} /$ day CLM7 simulates a diurnal cycle of precipitation and CAPE similar to CLM2.8 (not shown).

For the near future, both CLM2.8 and CLM7 project a significant net increase in the morning precipitation, which is most probably related to differences in the large-scale environment and/or nocturnal convection (Kapsch et al. 2012) since the morning maximum is usually driven by stratiform precipitation (Berg et al. 2013). Moreover, the afternoon maximum slightly decreases in intensity especially for CLM2.8. For events occurring within the same day, a too early onset or an overestimation of precipitation in the morning could inhibit or constrain the atmosphere for more intense events in the afternoon.

The variations in mean precipitation intensities in Fig. 10 top could be attributed to the projected changes in the atmospheric potential instability (i.e. KO-index) and vertical velocity at $500 \mathrm{hPa}$ (Fig. 10 bottom). In particular, for CLM2.8, where no significant changes in CAPE and low-level vertical velocity are observed, KO-index indicates a destabilization of the atmosphere in combination with an increase in the morning vertical velocity at $500 \mathrm{hPa}$. This is indicative of favourable atmospheric conditions and an increase of the potential for deep convection to occur as a consequence of large-scale forcing, in agreement with the increase in precipitation found in the morning. For CLM7, CAPE is projected not to change in the morning but to decrease in the afternoon, while the KO-index shows similar performance in the morning and a more unstable atmosphere in the afternoon. Meanwhile, a strong increase for vertical velocity in the morning and slight decrease in the afternoon is seen at $500 \mathrm{hPa}$ in agreement with the identified precipitation changes. The differences in CAPE between the two resolutions could be traced back to significant differences in mean specific humidity and temperature in the lower-levels of the troposphere.

The 100 days with the most intense hourly precipitation are selected for each simulation to verify that the above-presented results do not depend on the specific threshold used and to have a fairer comparison between CLM2.8 and CLM7. The so obtained diurnal cycles are very similar to Fig. 10 but CAPE and KO-index show much higher absolute values (i.e. CAPE to a maximum of $600 \mathrm{~J} /$ $\mathrm{kg}$ and $\mathrm{KO}$-index varying between 4 and $6 \mathrm{~K}$ in absolute value), thus leading to the conclusion that extreme hourly precipitation is mainly related to convective precipitation in the region and period investigated. Note that in this case the two resolutions show the same diurnal cycle for the KOindex, while they diverge in the climate change signal for CAPE as seen in Fig. 10. For the same 100 days, Fig. 11 shows that for CLM2. 8 the daily precipitation above $30 \mathrm{~mm}$ becomes stronger in the near future in good agreement with the daily IDF for wet days (Fig. 3 left). CLM7 provides a similar signal but weaker signal with less extreme precipitation. The future changes in hourly precipitation seem to be more related to a shift in the timing of the events (more in the morning than in the afternoon) rather than in their intensity.

\section{Summary and conclusions}

In the present study, we assess the effects of using simulations from a convection-permitting model in contrast to a coarser parameterized RCM on the climate change projections in summer. In particular, we compared 30-year timeslice simulations for the periods 1970-2000 and 2021-2050 for a strong orographically varying region of southwestern Germany. The paper presents the future changes in the precipitation pattern, and attempts to identify the possible drivers for the detected changes by investigating the atmospheric conditions leading to convection.

A decrease in mean precipitation up to $15 \%$ is projected in the investigation area for the near future in line with previous literature (Ban et al. 2015). However, this result seems to be related more to natural variability rather than 
climate change given the small significance of the change, and supported by the analysis in Wagner et al. (2012). The averaging process for the calculation of mean precipitation leads to a compensation of two opposing trends: a decrease in the percentage of wet days by $\sim 5 \%$, and an increase up to respectively 20 and $24 \%$ in the mean precipitation calculated for wet days and very strong precipitation days. Contrary to Ban et al. (2015), we found considerable differences in the spatial pattern of precipitation changes between resolutions for all thresholds.

The intensification of the more intense precipitation becomes more evident when looking at the IDF of daily precipitation intensities. In particular, the models project a significant increase for precipitation intensities above $50 \mathrm{~mm} /$ day $(70 \mathrm{~mm} /$ day) for CLM2.8 (CLM7) at the cost of the lower intensities. Similarly on hourly resolution, we found for both simulations an increased probability of precipitation intensities above $\sim 2 \mathrm{~mm} / \mathrm{h}$ due to an intensification of the morning precipitation.

For the near future scenario, the models project a significant increase of high-intensity events of both short and long durations, while lower intensity events decrease in line with the increase in the percentage of dry hours and dry periods. The coarser parameterised model, CLM7, well represents these changes besides slightly underestimating the more extreme events, which is linked to its tendency to underestimate hourly precipitation (Fosser et al. 2015). The relatively high resolution of CLM7 probably consents to represent the larger convective systems, which are not resolved at slightly coarser resolutions.

The analysis of the diurnal cycle of precipitation in relation to convective-related indices (i.e. CAPE and KOindex) and vertical velocity at low- and upper-atmospheric levels are used to identify possible reasons behind the future changes in precipitation. Considering only wet days, the models project a general shift towards higher precipitation intensities in line with the increase of mean wet precipitation and the precipitation intensity IDF at sub-daily resolution. A more unstable atmosphere, together with the increase in IWV, could justify this increase. In particular for CLM2.8, higher probability of CAPE between 200 and $1000 \mathrm{~J} / \mathrm{kg}$ between 00:00 and 05:00 and above $2000 \mathrm{~J} / \mathrm{kg}$ in the time interval 12:00-17:00 could lead respectively to an increase of low to medium intensity precipitation and heavier events as seen for the IDF of precipitation at subdaily scale. Meanwhile, the changes in the diurnal cycle of vertical velocity at $500 \mathrm{hPa}$ projected for the near future seem to indicate a different representation of the large-scale environment, in agreement with previous findings (Kunz et al. 2009). In particular, the shift of the maximum vertical velocity peak at $500 \mathrm{hPa}$ to the same time as the maximum potential instability (i.e. KO-index minimum) could be a driver for the intensification of deep convection due to large-scale forcing. Imposing a higher threshold, e.g. $50 \mathrm{~mm} /$ day, does not affect remarkably the shape of the diurnal cycles at convection-permitting resolution and the expected relation between CAPE and convective precipitation is well reproduced as seen in Fosser et al. (2015). For higher thresholds, CLM7 shows diurnal cycles of precipitation and CAPE very similar to CLM2.8, suggesting that CLM7 is able to resolve some of the larger convective plumes. Both CLM2.8 and CLM7 project a significant net increase in the morning precipitation probably due to convection forced by large-scale processes given the more potentially unstable atmosphere (i.e. more negative KOindex), especially for CLM2.8, and the stronger vertical velocity at $500 \mathrm{hPa}$ in the morning. The results obtained using a daily threshold of $50 \mathrm{~mm}$ are confirmed also when selecting the 100 days with the most intense hourly precipitation.

Unlike previous studies (Kendon et al. 2014; Ban et al. 2015), the parameterised-convection model, CLM7, and the convection-permitting model, CLM2.8, show very similar climate change signals. The differences between them are either not significant as in the case of the diurnal cycle of CAPE when considering days with a precipitation above $50 \mathrm{~mm}$; or attributable to the use of the Tiedtke parameterisation like in the representation of the diurnal cycles of precipitation, CAPE and cloud cover; or linked to a too coarse representation of orography that does not allow to accurately simulate small scale processes such as orographically-induced upward motion that can trigger convection. The similar results between the two resolutions obtained in contrast with previous literature (Kendon et al. 2014; Ban et al. 2015) could be linked to the relatively high resolution of CLM7 that seems to be able to resolve the most extreme convective events. Moreover, stronger differences between resolutions could appear toward the end of the century when the climate change signal becomes stronger, rather than in the near future, or being regionally dependent. On the other hand, also the small size of the $2.8 \mathrm{~km}$ domain could generate a too strong dependency on the driving coarser resolution and thus lead to similar results, although this feature is predominant in the winter season (Fosser et al. 2015). Furthermore, a small domain size has been found to impact negatively on the development of convection (Brisson et al. 2015), but in initial sensitivity experiments with also larger domain sizes, we have not found any significant impact on convection. This is likely related to the dominantly orographically induced convection in the area of investigation.

We can conclude that for southwestern Germany, and for the near future time period, convection-permitting models do not seem to bring added value to assessments of climate change in precipitation. Although the diurnal cycle is not well reproduced by the coarser CLM7 simulation, the 
climate change signals of this model are to a large extent consistent with the CLM2.8 simulation, and thus sufficient for most assessments. However, for further use of the model results in impact studies, the added value of CLM2.8 might be important. Moreover, for the region analysed here boundary-layer forced convection does not seem to be the main driver for changes in future precipitation. This is likely to be the main reason for the relatively good performance of the coarser resolution model. Other regions and future scenarios might be more sensitive. Moreover, the added values of convection-permitting resolution in the representation of the precipitation field were shown both in terms of hourly statistics and representation of the atmospheric fields leading to convective precipitation (Prein et al. 2015). Thus, convection-permitting resolution is in the long term a promising path in the investigation of the climate change signal and the base for the impact assessment models used in the planning of adaptation strategies to climate change. However, with the high computational costs at this resolution, coarser resolution models can bring more value in terms of longer simulation periods and large ensembles.

Acknowledgments G. F. acknowledges funding within the KLIWAproject "Bodenabtrag durch Wassererosion in Folge von Klimaveränderungen" from Bavarian State Ministry of the Environment and Public Health, Ministry of Economics, Climate Protection, Energy and Regional Planning of the German State Rheinland-Pfalz and Ministry of the Environment, Climate Protection and the Energy Sector Baden-Württemberg. G.F. also acknowledges funding from the French National Research Agency (ANR) project REMEMBER (contract ANR-12-SENV-001). S.K. acknowledges support by the German Ministry of Education and Research (BMBF). P.B. acknowledges support from SMHI. The CLM simulations were carried out at HLRS at the University of Stuttgart within the project "High resolution regional climate modelling" (HRCM). Finally, we would like to acknowledge the work of the R Development Core Team (2011), the developers of CDO. A special thanks to G. Messori and S. Chan for the useful discussion.

Open Access This article is distributed under the terms of the Creative Commons Attribution 4.0 International License (http://creativecommons.org/licenses/by/4.0/), which permits unrestricted use, distribution, and reproduction in any medium, provided you give appropriate credit to the original author(s) and the source, provide a link to the Creative Commons license, and indicate if changes were made.

\section{References}

Andersson T, Andersson M, Jacobsson C, Nilsson S (1989) Thermodynamic indices for forecasting thunderstorms in southern Sweden. Meteorol Mag 116:141-146

Baldauf M, Seifert A, Förstner J et al (2011) Operational convectivescale numerical weather prediction with the COSMO model: description and sensitivities. Mon Weather Rev. doi:10.1175/ MWR-D-10-05013.1

Ban N, Schmidli J, Schär C (2015) Heavy precipitation in a changing climate: does short-term summer precipitation increase faster? Geophys Res Lett 42:1165-1172. doi:10.1002/2014GL062588
Barthlott C, Corsmeier U, Meißner C et al (2006) The influence of mesoscale circulation systems on triggering convective cells over complex terrain. Atmos Res 81:150-175. doi:10.1016/j. atmosres.2005.11.010

Berg P, Wagner S, Kunstmann H, Schädler G (2012) High resolution regional climate model simulations for Germany: part I-validation. Clim Dyn 40:401-414. doi:10.1007/s00382-012-1508-8

Berg P, Moseley C, Haerter JO (2013) Strong increase in convective precipitation in response to higher temperatures. Nat Geosci 6:181-185. doi:10.1038/ngeo1731

Boberg F, Berg P, Thejll P et al (2009) Improved confidence in climate change projections of precipitation evaluated using daily statistics from the PRUDENCE ensemble. Clim Dyn 32:10971106. doi:10.1007/s00382-008-0446-y

Boberg F, Berg P, Thejll P et al (2010) Improved confidence in climate change projections of precipitation further evaluated using daily statistics from ENSEMBLES models. Clim Dyn 35:15091520. doi:10.1007/s00382-009-0683-8

Böhm U, Kücken M, Ahrens W, et al (2006) CLM-the climate version of LM: brief description and long-term applications. COSMO Newsletter No. 6, Deutscher Wetterdienst, Offenbach

Bolton D (1980) The computation of equivalent potential temperature. Mon Weather Rev 108:1046-1053. doi:10.1175/1520-0493(1980)108<1046:TCOEPT>2.0.CO;2

Brisson E, Demuzere M, Van Lipzig N (2015) Modelling strategies for performing convection-permitting climate simulations. Meteorol Z. doi:10.1127/metz/2015/0598

Brockhaus P, Lüthi D, Schär C (2008) Aspects of the diurnal cycle in a regional climate model. Meteorol Z 17:433-443. doi:10.1127/0941-2948/2008/0316

Chan SC, Kendon EJ, Roberts NM et al (2015) Downturn in scaling of UK extreme rainfall with temperature for future hottest days. Nat Geosci 9:24-28. doi:10.1038/ngeo2596

Christensen JH, Christensen OB (2007) A summary of the PRUDENCE model projections of changes in European climate by the end of this century. Clim Change 81:7-30. doi:10.1007/ s10584-006-9210-7

Christensen JH, Hewitson B, Busuioc A, et al (2007) Regional climate projections. Clim. Chang. 2007 Phys Sci Basis Contrib Work Gr. I to Fourth Assess. Rep Intergov Panel Clim Chang Cambridge University Press, Cambridge, UK and New York, NY, USA, pp 847-940

Déqué M, Jones RG, Wild M et al (2005) Global high resolution versus Limited Area Model climate change projections over Europe: quantifying confidence level from PRUDENCE results. Clim Dyn 25:653-670. doi:10.1007/s00382-005-0052-1

Déqué M, Rowell DP, Lüthi D et al (2007) An intercomparison of regional climate simulations for Europe: assessing uncertainties in model projections. Clim Change 81:53-70. doi:10.1007/ s10584-006-9228-x

Doms G, Förstner J, Heise E et al (2011) A description of the nonhydrostatic regional COSMO model. Part II: physical parameterization. Deutscher Wetterdienst, Offenbach

Efron B, Tibshirani RJ (1993) An introduction to the bootstrap. Chapman \& Hall, New York

Emanuel KA (1994) Atmospheric convection. Oxford University Press, New York

Feldmann H, Früh B, Schädler G et al (2008) Evaluation of the precipitation for South-western Germany from high resolution simulations with regional climate models. Meteorol Z 17:455-465. doi:10.1127/0941-2948/2008/0295

Feldmann H, Schädler G, Panitz H-J, Kottmeier C (2013) Near future changes of extreme precipitation over complex terrain in Central Europe derived from high resolution RCM ensemble simulations. Int J Climatol 33:1964-1977. doi:10.1002/joc.3564 
Fosser G (2014) Precipitation statistics from regional climate model at resolutions relevant for soil erosion. KIT Scientific Publishing, Karlsruhe

Fosser G, Khodayar S, Berg P (2015) Benefit of convection permitting climate model simulations in the representation of convective precipitation. Clim Dyn. doi:10.1007/s00382-014-2242-1

Giorgi F, Bi X, Pal J (2004) Mean, interannual variability and trends in a regional climate change experiment over Europe. II: climate change scenarios (2071-2100). Clim Dyn 23:839-858. doi:10.1007/s00382-004-0467-0

Jaeger EB, Anders I, Lüthi D et al (2008) Analysis of ERA40driven CLM simulations for Europe. Meteorol Z 17:349-367. doi:10.1127/0941-2948/2008/0301

Johns RH, Doswell CA (1992) Severe local storms forecasting. Weather Forecast 7:588-612. doi:10.1175/1520-0434(1992)007<0588:SLS $\mathrm{F}>2.0 . \mathrm{CO} ; 2$

Kapsch ML, Kunz M, Vitolo R, Economou T (2012) Long-term trends of hail-related weather types in an ensemble of regional climate models using a Bayesian approach. J Geophys Res Atmos. doi:1 0.1029/2011JD017185

Kendon EJ, Roberts NM, Fowler HJ et al (2014) Heavier summer downpours with climate change revealed by weather forecast resolution model. Nat Clim Chang 4:570-576. doi:10.1038/ nclimate 2258

Kessler E (1995) On the continuity and distribution of water substance in atmospheric circulations. Atmos Res 38:109-145. doi:10.1016/0169-8095(94)00090-Z

Khodayar S (2009) High-resolution analysis of the initiation of deep convection forced by boundary layer processes. PhD Thesis. Institute for Meteorology and Climate Research. Karlsruhe Institute of Technology

Khodayar S, Kalthoff N, Wickert J et al (2010) The increase of spatial data resolution for the detection of the initiation of convection. A case study from CSIP. Meteorol Z 19:179-198. doi:10.1127/0941-2948/2010/0439

Khodayar S, Kalthoff N, Schädler G (2013) The impact of soil moisture variability on seasonal convective precipitation simulations. Part I: validation, feedbacks, and realistic initialisation. Meteorol Z 22:489-505. doi:10.1127/0941-2948/2013/0403

Khodayar S, Sehlinger A, Feldmann H, Kottmeier C (2014) Sensitivity of soil moisture initialization for decadal predictions under different regional climatic conditions in Europe. Int J Climatol. doi:10.1002/joc.4096

Klein Tank AMG, Zwiers FW, Zhang X (2009) Guidelines on Analysis of extremes in a changing climate in support of informed decisions for adaptation. Climate Data and Monitoring WCDMP-No. 72, WMO-TD No. 1500. Climate Data and Monitoring WCDMP-No. 72, WMO-TD No. 1500

Kunz M, Sander J, Kottmeier C (2009) Recent trends of thunderstorm and hailstorm frequency and their relation to atmospheric characteristics in southwest Germany. Int J Climatol 29:2283-2297. doi: $10.1002 /$ joc. 1865

Lenderink G, van Meijgaard E (2008) Increase in hourly precipitation extremes beyond expectations from temperature changes. Nat Geosci 1:511-514. doi:10.1038/ngeo262
Moncrieff MW, Miller MJ (1976) The dynamics and simulation of tropical cumulonimbus and squall lines. Q J R Meteorol Soc 102:373-394. doi:10.1002/qj.49710243208

Nakicenovic N, et al (2000) Special report on emissions scenarios: a special report of working group III of the intergovernmental panel on climate change, Cambridge University Press, Cambridge, UK, 599 pp. http://www.grida.no/climate/ipcc/emission/ index.htm

Prein AF, Gobiet A, Suklitsch M et al (2013) Added value of convection permitting seasonal simulations. Clim Dyn 41:2655-2677. doi:10.1007/s00382-013-1744-6

Prein AF, Langhans W, Fosser $G$ et al (2015) A review on regional convection-permitting climate modeling: demonstrations, prospects, and challenges. Rev Geophys 53:323-361. doi:10.1002/2 014RG000475

Reichler T, Kim J (2008) How well do coupled models simulate today's climate? Bull Am Meteorol Soc 89:303-311. doi:10.1175/BAMS-89-3-303

Ritter B, Geleyn J-F (1992) A comprehensive radiation scheme for numerical weather prediction models with potential applications in climate simulations. Mon Weather Rev 120:303-325. doi:10.1175/1520-0493(1992)120<0303:ACRSFN>2.0.CO;2

Roeckner E, Bäuml G, Bonaventura L, et al (2003) The atmospheric general circulation model ECHM5: part 1. Technical report 349, Max Planck Institute for Meteorology, Hamburg

Roeckner E, Lautenschlager M, Schneider H (2006) IPCC-AR4 MPIECHAM5_T63L31 MPI-OM_GR1.5L40 20C3 M run no.1: atmosphere 6 HOUR values MPImet/MaD Germany. World Data Cent Clim. doi:10.1594/WDCC/EH5-T63L31_OM-GR1.5L40_20C_1_6H

Steppeler J, Doms G, Schättler U et al (2003) Meso-gamma scale forecasts using the nonhydrostatic model LM. Meteorol Atmos Phys 82:75-96. doi:10.1007/s00703-001-0592-9

Tiedtke M (1989) A comprehensive mass flux scheme for cumulus parameterization in large-scale models. Mon Weather Rev 117:1779-1800. doi:10.1175/1520-0493(1989)117<1779:ACM $\mathrm{FSF}>2.0 . \mathrm{CO} ; 2$

Tölle MH, Gutjahr O, Busch G, Thiele JC (2014) Increasing bioenergy production on arable land: does the regional and local climate respond? Germany as a case study. J Geophys Res Atmos 119:2711-2724. doi:10.1002/2013JD020877

Trenberth KE, Dai A, Rasmussen RM, Parsons DB (2003) The changing character of precipitation. Bull Am Meteorol Soc 84:12051217. doi:10.1175/BAMS-84-9-1205

Wagner S, Berg P, Schädler G, Kunstmann H (2012) High resolution regional climate model simulations for Germany: part II-projected climate changes. Clim Dyn 40:415-427. doi:10.1007/ s00382-012-1510-1

Weckwerth TM (2000) The effect of small-scale moisture variability on thunderstorm initiation. Mon Weather Rev 128:4017-4030. doi:10.1175/1520-0493(2000)129<4017:TEOSSM>2.0.CO;2

Westra S, Fowler HJ, Evans JP et al (2014) Future changes to the intensity and frequency of short-duration extreme rainfall. Rev Geophys 52:522-555. doi:10.1002/2014RG000464 